\title{
Synergy between exergy and regional planning
}

\author{
L. Gommans ${ }^{1,2,3,4}$ \& A. van den Dobbelsteen ${ }^{1}$ \\ ${ }^{1}$ Climate Design Group, Faculty of Architecture, \\ Delft University of Technology, The Netherlands. \\ ${ }^{2}$ Faculty of Architecture, Delft University of Technology, \\ The Netherlands \\ ${ }^{3}$ Faculty of the Built Environment, Hogeschool Zuyd, \\ Heerlen, The Netherlands \\ ${ }^{4}$ BOOM, Office for Research and Design for the Environment, \\ Maastricht/Delft, The Netherlands
}

\begin{abstract}
The realisation of a sustainable energy supply is an essential condition for achieving sustainability in society. About $30-40 \%$ of world energy is used in the built environment. In the past, energy-saving efforts were aimed on the one hand at reducing energy demand (e.g. improved insulation) and improving energy efficiency (e.g. high-performance gas heaters). On the other hand, effort has been put into the development and implementation of sustainable energy technology. Innovations on energy systems at a scale surpassing that of individual buildings have received relatively little attention. The current system of energy supply and use under-utilises the local and regional potential for self-sufficiency. Highquality energy is still often used for energy conversion processes requiring only low-quality energy. Instead of aiming for low energy losses in such processes, it may be more effective in terms of sustainability, to minimise exergy losses. A key objective of a low-exergy approach in a cascade of energy conversion processes is to minimise the amount of primary energy used by minimising exergy losses at each stage. Until now the low-exergy approach has been studied at the level of individual appliances or at most at single-building scale. However, given the potential of the total energy chain, exergy use should be implemented on a regional scale. This creates new opportunities for energy-savings. This paper gives examples and possibilities of a low-exergy approach at a regional scale that can lead to further energy-saving gains.

Keywords: energy, exergy, cascading, local potentials, waste energy, regional planning, energy transport, energy storage, energy conversion.
\end{abstract}




\section{Introduction}

\subsection{Low-exergy design}

According to the $2^{\text {nd }}$ Law of Thermodynamics, all processes tend toward an increasing level of entropy. As entropy is generated, exergy is reduced. Exergy is the useful part in energy that can be used to perform work, a measure of energy quality. The low-exergy principle strives for the reduction of exergy losses in and between the process steps of the energy cycle. The quintessence of this is that energy of a high-quality level (great exergy) should be used only for highgrade functions - e.g. heavy industries - before it evolves into a lower-quality state. Waste energy (entropy) from high-grade functions can still be used in lower-grade functions - e.g. horticulture and housing. Thus, a cascade of energy flows can be developed, serving more functions with the same amount of primary energy than in our current system. This hierarchic cascading of energy qualities touches the essence of ecology and can also be applied to material, water and food cycles.

The low-exergy principle can be applied to many scales of spatial design: region, city, district and building. It implies the concentration or mixing of functions, each embodying one of the steps in the cascade. Heat should not be transported over long distances: heat losses would be too big. This however suggests a radical shift from the separation of functions by present-day planning: horticulture near industry, residences near horticulture, or even integrated into them.

Coupling low-exergy design to spatial planning requires thorough analysis of a region or city. At present, there is no adequate design tool to support and guide sustainable spatial planning on a regional scale, which incorporates both a lowexergy approach and deployment of local potentials for energy generation.

\subsection{SREX}

The SREX (Synergy between Regional Planning and Exergy) project, aims at the development of a regional and urban low-exergy system that leads to an optimal use of energy resources (Roo et al., [6]). The project is conducted by the Dutch universities of Groningen, Wageningen and Delft, and it is funded by SenterNovem, the Dutch ministerial agency for energy and the environment. The researchers study the consequences of a low-exergy system to the relations between spatial functions at the urban, super-urban and regional level.

The Climate Design Group of Delft University of Technology is responsible for the SREX work package named "System analysis of regional energy planning". Within this work package a design tool will be developed for the support of regional and urban low-exergy design.

In regards to the incorporation of exergy principles in regional spatial planning explorative studies have been carried out for the Northern Netherlands, as reported by Roggema et al. [5], and more recently for the Province of Groningen, as reported by Dobbelsteen et al. [1]. These studies led to a 
methodology of energy potential mapping. This will be briefly discussed in the following chapter. These studies form a useful starting-point for the development of a generic technical design tool for regional planning.

\section{Methodology}

\subsection{Disentangling the exergy problem}

There are several aspects related to the current approach to exergy and energyefficiency in building:

- Systems: energy policy and energy conservation measures are focused primarily and too narrowly on improving single process steps of the energy chain, such as the efficiency of equipment. Insufficient attention is given to improvements and innovations to energy systems as a whole.

- Scale: energy supply is controlled on a national or at least regional scale, whilst improvements are carried out mostly on a single-building scale. The intermediate regional, super-urban and urban scale levels carry considerable untapped potential for improvement.

- Available resources: because of the national supply, locally available energy resources are insufficiently seized in spatial planning.

- Cascade: spatial planning policy and practice do not aim at organising flows of (waste) energy (yet also of water and other material flows) to minimise energy and exergy losses, whereas energy demand can be substantially reduced here.

- Energy flows: energy flows are generally considered in terms of energy carriers such as fossil fuel, electricity or heat. Waste material flows also carry energy, which can be put to use if convertible, becoming a significant solution to regional low-exergy planning.

- Theory: the thermodynamic theory of exergy is unpractical for use in spatial planning and the design of regions, cities and buildings. There is no clear link between space and exergy, although climate change and energy depletion demand for such.

A first step to the dissolution of these problems is to connect energy-related issues to spatial planning, by means of energy potential maps.

\subsection{Energy potential maps from Grounds for Change}

The methodology of energy potential mapping was initiated during the Grounds for Change research project. The regional design team of this projects drew maps on which an inventory of specific climatic, geomorphologic, natural, technical and (agri)cultural features were depicted. These characteristics involve strengths and weaknesses in terms of local potentials for energetic self-provision. The potential maps as such do not give immediate directives for spatial interventions, but they do provide a clear and simple image of the local availability of certain energy resources, the natural riches which in some cases are already deployed, but which in most cases can still be seized. Partly based on these maps, a new 
sustainable map was drawn of the Northern Netherlands, on which climate change and energy had been coupled to spatial interventions. Energy potential maps were discussed by Dobbelsteen et al. [1,5]. Figure 1 gives the potential maps from Grounds for Change.

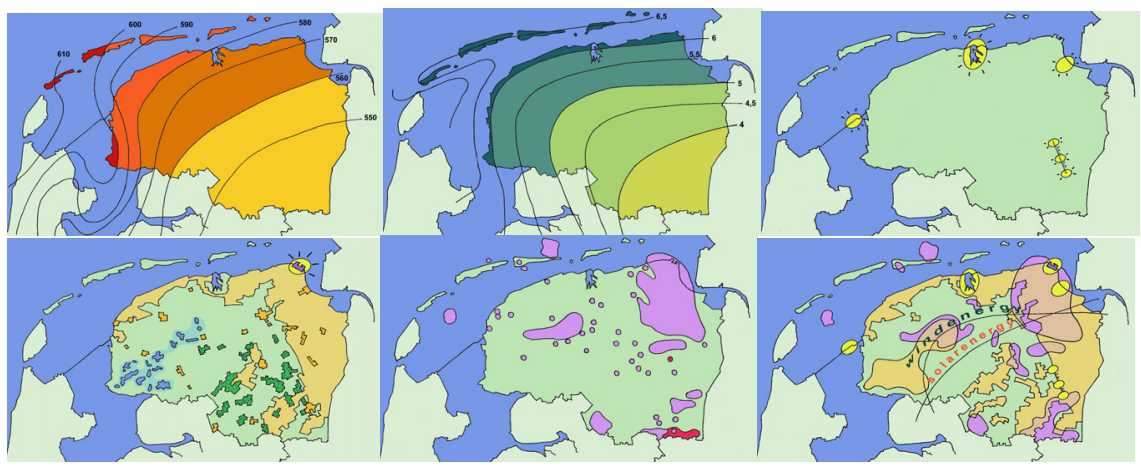

Figure 1: Energy potential maps from the Grounds for Change project, left to right and top to bottom: solar potential map, wind potential map, water potential map, biomass potential map, underground potential map and the overlay map.

\subsection{Energy potential maps from the POP energy project}

The initial potential maps evolving from Grounds for Change were based on separate energy resources. For the new provincial environmental plan (POP) of Groningen, which needed to be based better on climate change expectations and sustainable provision of energy, the methodology was enhanced and therefore altered. The structured analysis of the province commenced with an investigation of general characteristics that may influence energy potentials: topographic, historic, climatic and geomorphologic features, as well as data of the landscape and land use. Sometimes these characteristics could be given in so-called basic maps.

The basic maps were converted to maps that combined energy resources and their potential to specific energy forms (potentials for fuels, electricity, heat and $\mathrm{CO}_{2}$ capture). Each of these energy forms got an energy potential map that combined the best potentials of all resources. See figure 2 .

\section{Waste energy}

\subsection{What is waste energy?}

Energy potential mapping makes the natural energy resources visible in a certain region. When we try to apply the low-exergy approach to the regional scale, we need to look for opportunities to make energy cascades. Therefore, production spots of waste energy should be located, as well as areas where this waste energy can be used for another purpose. 


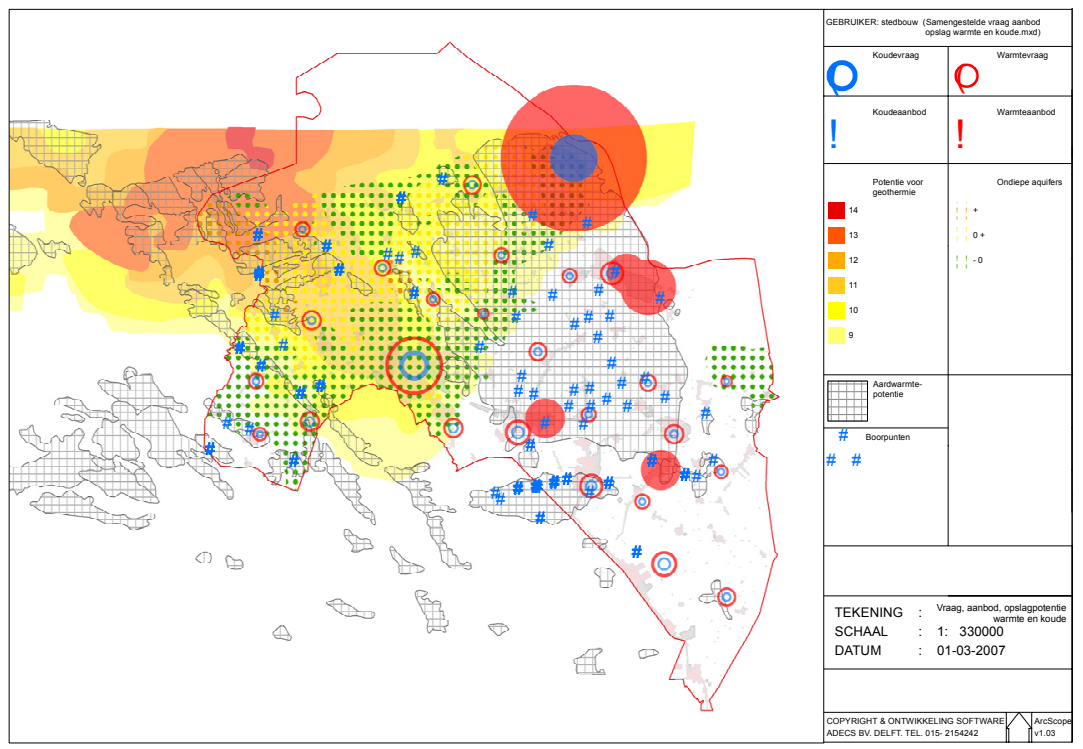

Figure 2: One of the energy potential map from the POP study for the Province of Groningen: combined heat and cold potential map.

Waste energy should be interpreted broadly. Just as waste heat from a power plant, wind or solar energy that is not captured can also be considered as waste energy. For instance, the built environment produces waste energy in the form of faeces that is delivered to a waste water treatment plant by the sewage system. Faeces contain waste heat and organic material that can be converted into useful energy. Other (organic) waste produced in the built environment, biomass from agriculture and by-products from industrial processes can also be converted into energy. For instance, waste materials of the paper industry can be converted to bio-ethanol. Methane gas can be produced from potato peels through fermentation. Even the maintenance of nature preserves gives rise to potentially useful waste flows, because these areas thrive when nutrients are periodically removed. Organic waste, e.g. from cuttings, is a fine source of energy.

These often are many untapped flows of matter and energy in the region. Usage of waste flows for the generation of energy leads to a decrease in pressure on the environment in two main ways. Firstly, unfunctional waste is made useful, so there's less waste. Secondly, the demand for fossil fuel decreases, and if biomass is replaced by new growth, a $\mathrm{CO}_{2}$-neutral situation will occurs, which is not possible with fossil fuels.

\subsection{Wrong energy, right conversion}

The use of waste energy as input to another process is not new. This double use of energy occurs, for instance, in waste water treatment plants, where methane 
gas extracted from sewage is used to generate electricity and sometimes heat for the sewage treatment processes and for the plant offices. Another example is combined heat and power generation (CHP) by means of which waste heat is distributed to building for space heating. Nonetheless, insufficient use is made of the possibilities abound. Factors that probably contribute to the under-exploitation of available energy are the infrastructure required, the limited technical expertise of the stakeholders, and the restricted scale of operation. A tool for the optimal deployment of waste flows, combined with analysis of regional energy potentials, should enable the design of energy systems at a regional scale that lead to reduced consumption of fossil fuel.

\section{The right energy form at the right time in the right place}

\subsection{The right energy form}

For a different approach to the regional energy system, a survey is needed on the energy demand in terms of quantity and quality $[4,7]$. By energy quality we refer to the exergy value, the particular form required (electricity, heat, chemical etc.) and the phase of the energy carrying medium (fluid, solid, gas). The energy required is not always available in the desired form, in which case conversion is necessary. Practical expertise is necessary of this conversion process, including knowledge of efficiency, costs and space requirements.

For the mapping of (waste) energy potentials it is necessary to know which forms of (waste) energy can be harvested and for which use. Expertise for this step is not always accessible and sometimes requires innovation. For instance, the bio-technology industry still regularly finds new ways, assisted by enzymes and bacteria, to convert certain materials into usable carriers of energy [8]. An overview of existing energy conversion processes will clarify which forms of (waste) energy can be converted to a usable form, and provide basic information about the associated costs and practical aspects of the conversion process.

\subsection{The right place}

In order to establish a working energy system the distances between sites of production, conversion and demand must be small enough to make transport of the energy feasible in terms of energy efficiency, space and costs. Infrastructure specifically for the purpose of energy transport may be possible.

Each method of transporting energy has characteristic features. Electrical energy can be transported at high voltage over large distances with relatively little losses. Transport of heat over larger distances however quickly reaches a point where the energy losses exceed the energy content. The losses are partly transmission losses to the environment and partly losses incurred by displacing the energy carrier (e.g. pump losses). Energy carriers in a solid or fluid state (e.g. wood products or liquid gas) can be transported by road, rail or waterways. Every method of transport has a price. 
The right place to generate electricity may be disputed. Should this be the place where, for example, biomass is available? Or is it the place where biomass or some other fuel can be easily delivered? Or should it be close to areas of living, where waste heat can be used for space heating? Or should it be at some location in-between? Every location has its pros and cons in terms of logistics, efficiency, public inconvenience, transport losses etc. For a well-deliberated decision on the matching of supply and demand of energy and the location of conversion, it is essential that the characteristics of the possible methods of transport are known.

\subsection{The right time}

Finally, timing can be an obstacle in realising a working energy system. Usable energy may be available in the right amount at the right place, but at the wrong time, necessitating energy storage for a short or long term. For instance, photovoltaic systems may require an overnight storage for electricity generated during the day, for use at night (e.g. lighting). Long-term seasonal energy storage will meet the demand for space heating in winter, with excess solar energy captured during summer. Similarly, waste heat continuously produced by industrial processes may be usable only in winter.

Storing energy is always associated with energy losses and besides, costs, space and energy (for loading and unloading). Each form of storage has its own characteristics. Fuels such as fossil fuels, plant-based oils, bio-ethanol, but also biomass in general are the highest form of exergy. They essentially are chemical stores from which energy can be released by combustion or in another way. As a result of their energy density they require relatively little space. There are many ways to store heat, such as in the thermal mass of buildings or underground heat buffers. Storage of electricity is more difficult than of heat. The electrical grid is sometimes used, but this is only possible as long as the changeable power from wind turbines or solar systems is relatively limited. An increasing share of electrical energy produced by the sun and wind will require a different solution for storage, possibly hydrogen. The selection of an appropriate energy storage method is determined to a large extent by the form of the energy required and by the duration of storage. Locations and regions will vary in their particular requirements and potentials for storage.

\section{Case study: Stadspark Oranje Nassau (Heerlen, NL)}

In order to achieve maximum benefit from regional energy potentials and to establish energy cascades, a good spatial and temporal matching of energy supply and demand is essential. Beside creativity, this requires expert knowledge of energy conversion, transport and storage technology. In the suburban Stadspark Oranje Nassau (SON) of the city of Heerlen, in the southern part of The Netherlands, an energy plan was made for a zero-energy suburb [2, 3]. 


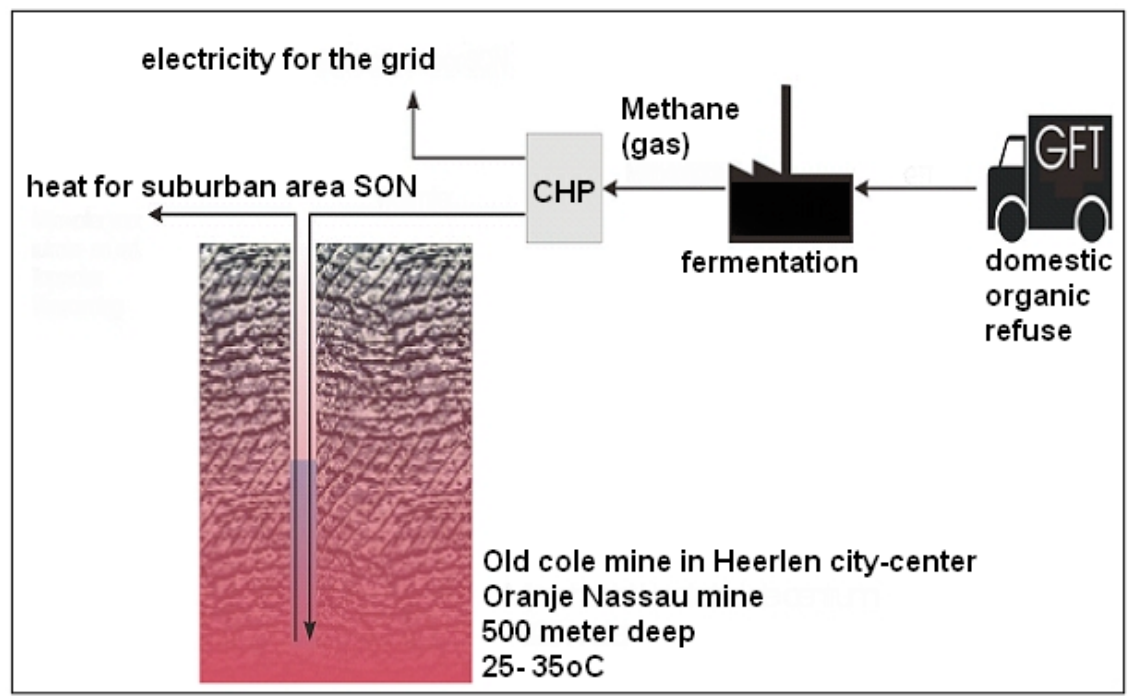

Figure 3: Domestic organic refuse is brought to an anaerobic digester, which produces methane that serves as fuel for a CHP plant. The CHP plant produces both heat and electricity. Electricity goes to the power grid. Heat energy is used for SON-living district in cold periods, or stored underground in the local mines in summertime. Thus, there is energetic equilibrium underground of withdrawal and replenishment.

The future suburb, close to the city centre, is located in the vicinity of deserted coal mine pits. An important objective of the energy plan is to supply the new buildings with sustainable energy. Part of the plan is to produce methane in an anaerobic fermenter, using domestic organic refuse from the whole region. The methane is used in a combined heat and power (CHP) generator to produce electricity for the grid and heat for the buildings in SON in wintertime. Until now domestic organic waste is transported by truck to a town $30 \mathrm{~km}$ away, where it is turned into compost, a commodity with an overly saturated market.

An obvious choice was to locate both the anaerobic digester and the CHP within the suburb, where the coal mine is located. However, this easily leads to traffic congestion caused by trucks going in and out of the area with domestic organic refuse and fermented waste. Moreover, the safety regulations for the anaerobic digester prohibit housing in the near vicinity, which is not economically feasible near the city centre. So, on second thought, it proved better to locate the anaerobic digester outside the suburb with good accessibility by road. With regard to electricity, the CHP plant could be located in the same area as transport of electricity through the power grid is possible with little energy loss. However, transport of CHP-generated heat back to the suburb implies unacceptable energy costs due to transmission and pump losses. Hence, it was best to locate the CHP plant within the suburb, and feed it methane 
through a pipeline from the fermentation plant. Transport of the methane costs considerably less energy than the transport of heat.

It is also possible to purify the fermentation gases and supply it to the local natural gas network. This alternative, which would cost slightly more energy because of the high gas pressures required, has the advantage that the existing network of natural gas pipelines can be used for transport. Another advantage to using the existing natural gas distribution network is that the fermentation plant can continue operation in summer, when the supply of domestic organic refuse reaches a maximum. Long-term storage of the organic waste leads to degradation of the energy content due to natural digestion, and thus is undesirable. For sufficiently small quantities of methane, absorption into the natural gas network should not be a problem.

Next step is that the heat produced in summer is stored until winter, since the CHP-plant output is greatest in summer when heat is barely needed. The heat could be stored in a central depot underground, but this leads to significant exergy losses at the start of the heating season, through transmission and sudden decrease in the underground temperature. The suburb lies on top of deserted mine tunnels going down to $500 \mathrm{~m}$ underground. These have watered out naturally with ground water of temperature between 25 and $35^{\circ} \mathrm{C}$. This allows storage of heat with low-exergy losses, since the ambient temperature is relatively high. In addition, in summer surplus heat energy from solar collectors can be stored in the mine tunnels.

\section{Conclusion}

Energy potential mapping is a useful instrument to visualise sustainable local potentials for energy provision. By mapping a region's energy potentials, matching energy supply and demand and applying energy cascades, the use of fossil fuels can be significantly reduced. Creativity combined with wellconsidered decisions, based on sufficient information and expert knowledge of energy conversion, transport and storage can thus lead to uncommon and environmentally sound solutions which also boost the local economy.

There is a need both for this expertise and for a technical design tool which makes it accessible, to enable well-deliberated choices to be made in this area. A pragmatic look at the characteristics and qualities of a region and a tool to show the possibilities for the region can inspire to innovate, which may be needed in a world facing climate change and energy depletion.

\section{References}

[1] Dobbelsteen A. van den, Jansen S. \& Timmeren A. van (2007), Omgevingsplan Groningen Energiegestuurd - ruimtelijke sturing door energiepotenties en warmtecascades (Delft: TU Delft)

[2] Gommans L., Broers W., Colpa E., Israels E., Talstra S., Duijvestein C. (2002), Energievisie Stadspark Oranje Nassau - Van zwarte naar groene energieleverancier (Municipality of Heerlen NL) [in Dutch] 
[3] Gommans L., Broers W., Zomerplaag J., Colpa E., Israels E (2003), Haalbaarheidsonderzoek Energievisie Stadspark Oranje Nassau - Van zwarte naar groene energieleverancier (Municipality of Heerlen NL) [in Dutch]

[4] Jong T.M. de (ed.), Moens M.J., Akker C. van den \& Steenbergen C.M. (2006), Sun Wind Water Earth Life Living - Legends for design (Delft: Delft University of Technology, Faculty of Architecture)

[5] Roggema R., Dobbelsteen A. van den \& Stegenga K. (eds.) (2006), Pallet of Possibilities (Province of Groningen)

[6] Roo G. de, Jong M. de, Roggema R., Dobbelsteen A. van den, Linden K. van der, Rovers, R., Timmermans W., Koh J., Simmelink E. (2005), SREX Synergy of Regional Planning and Exergy (University of Groningen)

[7] SenterNovem (2006), Cijfers en tabellen 2006 - Kompas energiebewust wonen en werken (Utrecht: Senternovem) [in Dutch]

[8] Technologisch instituut Koninklijke Vlaamse Ingenieurs Vereniging (TIKVIV), 2007, Innovative Bio-energy, Reader for conference Maastricht NL. 